\title{
A Study on the Factors Influencing the Satisfaction of College Users on Logistics Services under the Structural Equation Model: Example of Jingdong Logistics in China
}

\author{
Guoxing Zhang ${ }^{1}$, Jiamin Cai ${ }^{1}$, Yuhong Sun ${ }^{* 1, a}$ \\ ${ }^{1}$ Department of Business Administration Guangzhou College of Technology and Business, Guangzhou, Guangdong
}

\begin{abstract}
In this paper, the structural equation model is used to investigate the factors that affect the satisfaction of college students with Jingdong (JD) logistics. Based on the Swedish customer satisfaction index (SCSI) model and the American customer satisfaction index (ACSI) model, combined with their own actual needs, the model of college students' satisfaction with JD Logistics is redefined. In this way, the scale indicators of the questionnaire survey are set. Combined with the research and empirical analysis of relevant literature, the initial model hypothesis was constructed, and six path hypotheses were proposed. The reliability and validity analysis confirmed that the questionnaire scale had high reliability and structural validity, and the structural equation model is also carried out. The fitting degree test confirmed that the structural equation hypothesis model has a high degree of fit, and verified the hypothesis established in the article, and finally put forward some countermeasures and suggestions for improving the service system of JD Logistics.
\end{abstract}

\section{Introduction}

In recent years, JD.com's self-operated logistics system greatly shorten the company's operating costs and improved JD.com's market competitiveness, which is mainly due to JD.com's continuous improvement of customer satisfaction. As a concept of economic psychology, customer satisfaction cannot be directly measured and reflected, so this paper mainly uses structural equation models to analyze its influencing factors.

In determining the index of college users' satisfaction with JD.com, it draws on the current satisfaction index models that are highly recognized by academia: the SCSI model and the ACSI model. Among them, the Swedish satisfaction index model ( SCSB ) mainly divides customer satisfaction into five indicators, namely customer expectations, perceived performance, customer satisfaction, customer complaints and customer loyalty. The main psychological path is that customer expectations affect perceived performance and customer satisfaction, and perceived performance Affect customer satisfaction, customer satisfaction affects customer complaints and customer loyalty, customer complaints affect customer loyalty [1]. Fornell et al. constructed an ACSI model based on the SCSI model, and added a perceived quality factor on the basis of the SCSI model to make customers' perceived value at the same time [2]. After that, the customer satisfaction index model is widely used in specific industries [3-5].

Structural equation model [6-9] can realize the analysis of the relationship between multiple variables, which is different from the traditional linear regression model. The linear programming model ignores the relationship between independent variables. In the analysis of the actual situation, the influence of independent variables can often be used as an important factor to improve decision-making. Based on this, the article combined with related research literature, using structural equation model to analyze the factors affecting the satisfaction of JD logistics services, and provide some reference suggestions for JD logistics to improve the service system.

\section{Research methods and model building}

\subsection{Data collection}

Based on the SCSI model and the ACSI model, combined with the actual analysis needs, the satisfaction index of college student users on JD Logistics is determined according to the research situation. The main variable dimensions are enterprise perception, service quality, and customers. There are 11 variables in loyalty, customer complaints and overall satisfaction, as shown in Table 1:

Table1. Satisfaction Rating Scale of Collage Users on JD Logistics

\begin{tabular}{|c|c|}
\hline Evaluation index & Scale item \\
\hline \multirow{2}{*}{$\begin{array}{l}\text { Enterprise } \\
\text { perception }\end{array}$} & Good knowledge of JD Logistics \\
\cline { 2 - 2 } & Good understanding of the social image of JD \\
Logistics
\end{tabular}

$\mathrm{a}^{*}$ Corresponding AuthorE-mail: sunyh0508@foxmail.com 


\begin{tabular}{|c|c|}
\hline \multirow{4}{*}{ Service quality } & $\begin{array}{c}\text { I feel that the employee image of JD Logistics } \\
\text { is standardized }\end{array}$ \\
\hline & Goods can arrive on time using JD Logistics \\
\cline { 2 - 2 } & $\begin{array}{c}\text { Goods can be delivered completely using JD } \\
\text { Logistics }\end{array}$ \\
\cline { 2 - 2 } & Delivery staff has a good service attitude \\
\hline \multirow{3}{*}{$\begin{array}{c}\text { Return and exchange can be timely and } \\
\text { effective }\end{array}$} \\
\hline $\begin{array}{c}\text { Customer loyalty } \\
\text { complain }\end{array}$ & $\begin{array}{c}\text { After using JD Logistics, choose to use it next } \\
\text { time and within a period of time }\end{array}$ \\
\cline { 2 - 2 } & $\begin{array}{c}\text { I would recommend JD Logistics to others } \\
\text { around me }\end{array}$ \\
\hline Satisfaction & JD Logistics charges reasonable \\
\hline
\end{tabular}

This study analyzes the satisfaction of college users with JD logistics service distribution, and then analyzes the factors that affect the satisfaction of JD logistics service. The analysis target is college users, but the data acquisition process is more complicated and timeconsuming, so it is mainly selected college users in the main urban area of Guangzhou are used as samples to conduct research surveys, and the online distribution of questionnaires is used to ensure that the collected data is as representative as possible. In the end, we obtained various data such as the age of college users of different genders and grades in Guangzhou, online shopping consumption habits, various service indicators of JD logistics services and overall satisfaction.

\subsection{Structural equation modeling}

The general expression of the structural equation model includes two types of equations:

Measurement equation:

$$
\eta=C \eta+D \varepsilon+\zeta
$$

Structural equation:

$$
\begin{aligned}
& y=K_{y} \eta+\varepsilon \\
& x=K_{x} \zeta+\delta
\end{aligned}
$$

Among them, $\mathrm{C}$ and $\mathrm{D}$ are data matrix coefficients; $x$ is exogenous index vector; $\mathrm{y}$ is endogenous index vector; $K_{X}$ is the relationship between exogenous index and exogenous latent variable; $K_{y}$ is the relationship between endogenous index and exogenous latent variable; $\zeta$ is the residual of structural equation; $\delta$ is the error term of exogenous index; $\varepsilon$ is the error term of endogenous index [10].

Further, the following hypotheses that need to be tested are formulated for the relationship between the influencing factors of college users' satisfaction with JD Logistics services:

H1: Business perception has a significant effect on overall satisfaction;

$\mathrm{H} 2$ : Service quality has a significant effect on overall satisfaction;

H3: Customer complaints have a significant effect on overall satisfaction;
H4: Overall satisfaction has a significant effect on customer loyalty;

H5 : Service quality has a significant effect on business perception;

H6: Business perception has a significant effect on customer complaints.

\section{Model checking and analysis}

\subsection{Descriptive statistical analysis}

According to the nature of the research objects, a total of 248 valid questionnaires were distributed and collected in the form of online questionnaires among the college users in Guangzhou. Descriptive analysis of the data structure of the questionnaire from gender, grade, age of online shopping and monthly online shopping amount: Among them, the number of female cases is 179 , the number of male cases is 67, and the majority of women; the maximum number of junior students in the grade structure is 128 . The minimum age of senior students is 22 ; the age of online shopping for the sample data is mostly distributed in 2-5 years and 3-5 years, indicating that most of the sample data have certain online shopping experience; the monthly online shopping amount range is mostly 200-500 yuan, which further reflects the consumption situation of college users, which is in line with the actual situation.

\subsection{Scale reliability and validity analysis}

In order to verify the quality of the scale design, the consistency and stability of the broken test results, and to assess the impact of measurement errors on the test results, the reliability of the data is first analyzed. This work uses SPSS software to analyze the reliability of the influencing factor scale. The Crobach's Alpha value and the Cronbach's Alpha value are both 0.935 , so the analyzed data has a very high internal consistency, and the reliability is very strong.

The main validity test standard is to calculate the KMO value and Bartlett test value of the sample data. In this study, the KMO value is 0.938 , and the Bartlett sphericity test approximate chi-square is 1837.779 , with a significance value of $0.000<0.05$, indicating that college students are satisfied with JD Logistics The degree of influencing factors has good validity and is very suitable for factor analysis.

\subsection{Structural equation model fitting test}

Based on the reliability and validity analysis of the questionnaire scale data, it is confirmed that the scale has reasonable reliability and result validity. The AMOS 25.0 software is now used to target the relationship between college students and the factors affecting the satisfaction of JD Logistics and establish the conceptual structural equation model of the relationship between latent variable influence factors, then run the model. Analyze the 
satisfaction mechanism and the influence of latent variable influence factors through the path relationship between the variables and the output. The results of the model run are shown in Figure 1.

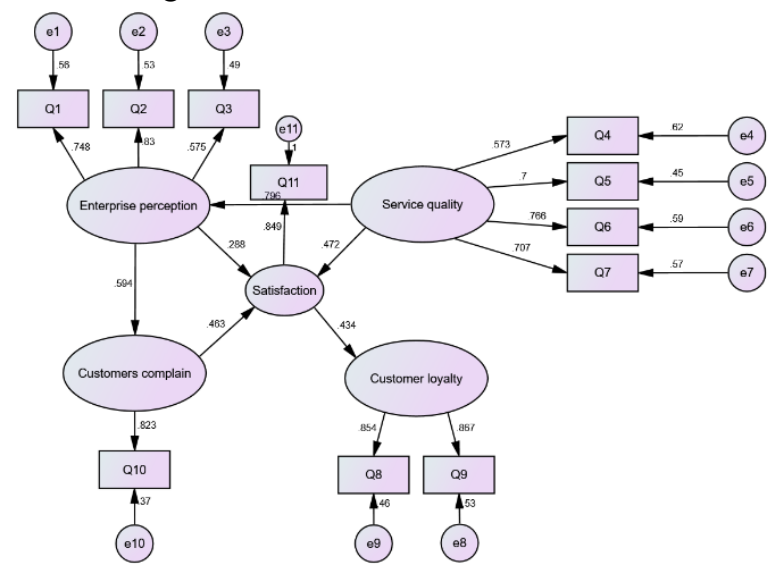

Fig1. Schematic diagram of path coefficient of structural equation model

After the model is established, it is necessary to test the fit of the model, that is, to estimate the parameters of the model to determine whether the series of indicators of the model meet the requirements of the result analysis. The fitting index that reflects the fit of the model usually includes the residual error. Absolute fitting indexes such as mean square and square root index, chi-square test, mean square of progressive residual and goodness-of-fit index; and relative fitting indexes such as standard fitting index and comparative fitting index.

Table2. Model fitting index

\begin{tabular}{|c|c|c|c|c|c|}
\hline Index & CMIN & DF & CMIN/DF & SRMR & GFI \\
\hline $\begin{array}{c}\text { Evaluation } \\
\text { standard }\end{array}$ & -- & -- & $<3$ & $<0.08$ & $>0.8$ \\
\hline Value & 72.47 & 68 & 1.732 & .047 & .982 \\
\hline $\begin{array}{c}\text { Fitting } \\
\text { situation }\end{array}$ & -- & -- & Good & Good & Good \\
\hline Index & AGFI & IFI & TLI & CFI \\
\hline $\begin{array}{c}\text { Evaluation } \\
\text { standard }\end{array}$ & $>0.8$ & $>0.9$ & $>0.9$ & $>0.9$ \\
\hline Value & .978 & .957 & .963 & .944 \\
\hline $\begin{array}{c}\text { Fitting } \\
\text { situation }\end{array}$ & \multicolumn{2}{|c|}{ Good } & Good & Good & Good \\
\hline
\end{tabular}

By observing the proposed test table, it can be seen that each parameter meets the standard, CMIN/D meets the requirements of less than 3, SRMR is less than 0.08 , GFI and AGFI meet the requirements of greater than 0.8 , and IFI, TLI, CFI are all greater than 0.9, indicating that the established model has a good fit degree. Therefore, the construction of the model is reasonable, and has certain significance for the result research.

Path analysis is performed on the hypothetical model. The hypothesis results are tested according to the path coefficients and significance levels to construct the covariance matrix of the variable data. By analyzing the path relationship of the indicators in the hypothetical model, the fit between the model and the variable data is judged.
Table3. Path Coefficient Table of Factors Influencing Collage Users' Satisfaction with JD Logistics

\begin{tabular}{|c|c|c|c|c|c|}
\hline Path & Estimate & S. E & C.R & P & Lable \\
\hline $\begin{array}{c}\text { Enterprise } \\
\text { perception } \\
\text {---> Satisfaction }\end{array}$ & .288 & .081 & 4.472 & $* * *$ & $\begin{array}{c}\text { Assumption 1 } \\
\text { holds }\end{array}$ \\
\hline $\begin{array}{c}\text { Service quality } \\
\text {---> Satisfaction }\end{array}$ & .472 & .078 & 5.583 & $* * *$ & $\begin{array}{c}\text { Assumption 2 } \\
\text { holds }\end{array}$ \\
\hline $\begin{array}{c}\text { Customers complain } \\
--->\text { Satisfaction }\end{array}$ & .463 & .068 & 3.162 & 0.001 & $\begin{array}{c}\text { Assumption 3 } \\
\text { holds }\end{array}$ \\
\hline $\begin{array}{c}\text { Satisfaction } \\
--->\text { Customer } \\
\text { loyalty }\end{array}$ & .434 & .06 & 5.461 & $* * *$ & $\begin{array}{c}\text { Assumption 4 } \\
\text { holds }\end{array}$ \\
\hline $\begin{array}{c}\text { Service quality---> } \\
\text { Enterprise } \\
\text { perception }\end{array}$ & .796 & .042 & 4.786 & $* * *$ & $\begin{array}{c}\text { Assumption 5 } \\
\text { holds }\end{array}$ \\
\hline $\begin{array}{c}\text { Enterprise } \\
\text { perception } \\
--->\text { Customers } \\
\text { complain }\end{array}$ & .594 & .052 & 5.563 & $* * *$ & $\begin{array}{c}\text { Assumption 6 } \\
\text { holds }\end{array}$ \\
\hline
\end{tabular}

The path coefficient and significance level between the indicators of the hypothetical model are shown in the Table3

H1: Enterprise perception has a significant impact on overall satisfaction, with a standardized coefficient of 0.288 and a probability $\mathrm{P}$ value of less than 0.05 , assuming it holds;

H2 : Service quality has a significant impact on overall satisfaction. The standardized coefficient is 0.472 , the probability $\mathrm{P}$ value is less than 0.05 , and the assumption is true;

H3: Customer complaints have a significant impact on overall satisfaction, the standardized coefficient is 0.463 , the probability $\mathrm{P}$ value is less than 0.05 , the assumption is true;

H4: Overall satisfaction has a significant impact on customer loyalty, the standardized coefficient is 0.434 , the probability $\mathrm{P}$ value is less than 0.05 , the assumption is true

H5: Service quality has a significant impact on business perception. The standardized coefficient is 0.796 , the probability $\mathrm{P}$ value is less than 0.05 , and the assumption is true;

H6: Enterprise perception has a significant effect on customer complaints. The standardized coefficient is 0.594 , the probability $\mathrm{P}$ value is less than 0.05 , and the assumption is true.

\section{Conclusions and Suggestions}

Through the inspection and analysis of the set structural equation model, the index parameters of the model fitting all meet the analysis standard, the fitting degree is good, the established model has a good fit, the set index and hypothesis structural models can be used for structural equation analysis. The study concludes that users' perceptions of JD Logistics' business perception, service quality, customer complaints and customer loyalty all affect their overall satisfaction with the enterprise. There are significant correlations among several variables, among which customers' satisfaction with JD Logistics Relatively impressive. Through the analysis of the final results, the main conclusions are:

- $\quad \mathrm{H} 1, \mathrm{H} 2$, and H3 hypotheses are established, that is, business perception, service quality, and 
customer complaints have a significant impact on overall satisfaction; H4, H5, and $\mathrm{H} 6$ hypothesis are established, that is, overall satisfaction has a significant impact on customer loyalty; services quality has a significant impact on business perception and business perception on customer complaints.

- According to the path coefficient table, the relationship between perceived business, service quality and customer complaint on overall satisfaction, of which the standardized coefficient of service quality is 0.472 is the highest level compared with perceived enterprise and customer complaint, indicating that service quality has an overall effect on overall satisfaction. With the greatest impact, companies need to focus on improving service quality, which can greatly improve overall satisfaction.

- There is a certain path relationship between service quality, perceived enterprise, and customer complaint, which is mainly manifested as a ring structure. Enterprises should make certain adjustments to the results of the three according to their own actual situation and the strength of the relationship between the three, to achieve a virtuous circle.

- $\quad$ Although the probabilistic P values of each path analysis of the factors affecting overall satisfaction indicate that the hypothesis is true, their standardized coefficients are not high and are all weakly correlated, indicating that the improvement of the three has certain limitations for improving overall enterprise satisfaction. In the actual adjustment, the enterprise needs to carry out certain experimental analysis on the critical value of the upgrade to achieve the best cost combination.

- In the Supply-Hub supply chain operation mechanism, operators need to use advanced technologies, such as cloud computing technology, to establish an information collaboration platform to reduce the channel cost of information collaboration and the risk of information collaboration.

\section{Acknowledgment}

This work was funded jointly by the Young Talents Project in Key Platform of Guangdong (2018WQNCX224) and the Guangzhou College of Technology and Business Project of Humanities and Social Sciences (KA201820). All simulations were carried out using the equipment provided by Gansu Provincial Computing Center.

\section{References}

1. M. D. Johnson, C. Fornell. "A framework for comparing customer satisfaction across individuals and product categories," North-Holland, vol. 12, 1991.

2. C. Fornell, M. D. Johnson, E. W. Anderson, et al. "The American Customer Satisfaction Index: Nature,
Purpose, and Findings," Journal of Marketing, vol. 60, pp. 7-18, 1996.

3. N. S. Terblanche. "An application of the American customer satisfaction index (ACSI) in the South African motor vehicle industry," South African Journal of Business Management, vol. 37, pp. 29-38, 2006.

4. S. Awwad, Mohammad. "An application of the American Customer Satisfaction Index (ACSI) in the Jordanian mobile phone sector," Tqm Journal, vol. 24, pp. 529-541, 2012.

5. American Customer Satisfaction Index; "Customer Satisfaction High with Full-Service Restaurants; Fast Food Chains on the Decline, ACSI Data Show," Food Weekly News, 2019.

6. J. T. Austin, L. M. Wolfle. "Annotated bibliography of structural equation modelling: technical work," The British journal of mathematical and statistical psychology, vol. 44, 1991.

7. Z. Zheng, Z. T. Gao, D. S. Li, et al. "Interaction between the atmospheric boundary layer and a standalone wind turbine in Gansu-Part II: Numerical analysis," SCIENCE CHINA Physics, Mechanics \& Astronomy, vol. 61, pp. 094712, 2018.

8. Z. T. Gao, Y. H. Sun, T. G. Wang. "Research on the loads of NREL 5MW wind turbine under stable atmospheric conditions," IOP Conference Series: Earth and Environmental Science, vol. 237, 2019.

9. Z. T. Gao, T. G. Wang. "Experimental validation and improvement of actuator line model in the large-eddy simulation of wind-turbine wakes," IOP Conference Series: Earth and Environmental Science, vol. 463, pp. 012113, 2020.

10. M. Melucci, A. Paggiaro. "Evaluation of information retrieval systems using structural equation modeling," Computer Science Review, 2019. 